\title{
Can Cd content in crops be controlled by Se fertilization? A meta-analysis and outline of $\mathrm{Cd}$ sequestration mechanisms
}

\author{
Marie-Cécile Affholder (D) Adam Flöhr • Holger Kirchmann
}

Received: 4 December 2018 / Accepted: 5 April 2019/Published online: 6 May 2019

(C) The Author(s) 2019

\begin{abstract}
Aim Cadmium mitigation in crops is a worldwide concern. Selenium application has been suggested as a potential solution to reduce cadmium concentration in plants, but published results were contradictory. We analysed literature data with respect to the effect of selenium addition on cadmium uptake and elucidated processes possibly involved.

Method A meta-analysis was performed on data collected from previously published studies presenting cadmium concentration in plants subjected to selenium treatments. Metaregression random models were run to test the impact of different factors. In addition, soil and crop inventory data exemplifying the natural variation of $\mathrm{Cd}$ and Se in soil were evaluated.

Results The results highlighted a significant reduction of cadmium concentration in crops after selenium addition. The reduction was dose-dependent for crops growing under aerobic, but not for plants cultivated under
\end{abstract}

Responsible Editor: Yong Chao Liang.

Electronic supplementary material The online version of this article (https://doi.org/10.1007/s11104-019-04078-x) contains supplementary material, which is available to authorized users.

M.-C. Affholder $(\triangle) \cdot$ H. Kirchmann

Department of Soil and Environment, Swedish University of Agricultural Sciences (SLU), Box 7014, 75007 Uppsala, Sweden e-mail: marie-cecile.affholder@slu.se

A. Flöhr

Department of Biosystems and Technology, Swedish University of Agricultural Sciences (SLU), Box 103, 23053 Alnarp, Sweden anoxic conditions such as rice. This suggests that different process can be involved.

Conclusion We demonstrated the potential of selenium fertilization to mitigate cadmium uptake and highlighted that for non-rice species, the main process seems to take place in the soil, while mechanisms in roots restricting uptake may be involved for all crops. The inventory data also indicated an impact of natural soil Se on $\mathrm{Cd}$ contents in crops.

Keywords Cadmium-selenium interaction . Metaregression $\cdot$ Shoots $\cdot$ Roots $\cdot$ Redox potential $\cdot$ Selenite $\cdot$ Selenate

\section{Introduction}

Cadmium is classified as a human carcinogen (IARC 1993) and dietary intake is considered a health risk that may cause kidney failure, bone demineralization and increased risk of cancer in the lung, endometrium, bladder, and breast (EFSA 2009). As a consequence, tolerable dietary intake of Cd was reduced by $65 \%$ from 7.5 to $2.5 \mu \mathrm{g} \mathrm{kg}^{-1}$ body weight and week (EFSA 2017). The restrictive standard for dietary $\mathrm{Cd}$ intake requires strategies to minimize uptake of $\mathrm{Cd}$ by crops but few are available: identification of fields with high Cd contents, liming of acid Cd-rich soils (Rizwan et al. 2016) and use of Cd-rich crops exclusively for fodder (Söderström and Eriksson 2013). A further measure proposed is application of selenium compounds (Se) to soil in order to reduce $\mathrm{Cd}$ uptake by crops being the focus of this paper. 
Selenium was identified as an essential element for mammals in the 1950s (Schwarz and Foltz 1957). Selenium deficiency was shown to increase the risk of cardiovascular diseases (Salonen et al. 1982). A newly revised recommendation by EFSA (2014) proposed a higher daily dietary Se intake, 70 instead of 50-60 $\mu \mathrm{g} \mathrm{Se}$ per person. Today, it is estimated that hundreds of millions of people have an inadequate dietary intake of Se (Combs 2001; Jones et al. 2017). The reason for low Se concentrations in food are low or very low Se concentrations in most parent materials rarely exceeding $0.1 \mathrm{mg} \mathrm{kg}^{-1}$ soil (Fordyce 2007). Diets rich in Se have shown to protect animals against Cd-toxicity (Zwolak and Zaporowska 2012). Crops and cereals in particular are a major Se source in diets (Rayman 2012).

Fertilizing crops with Se with the aim to decrease $\mathrm{Cd}$ uptake by crops could be a win-win situation: i) increasing Se in the diet and limiting Se deficiency, and ii) reducing $\mathrm{Cd}$ concentrations in crops and thereby dietary $\mathrm{Cd}$ intake and possible toxic effects of $\mathrm{Cd}$ in the body.

In this paper, existing literature about possible interactions between Se application and Cd uptake in the soilcrop-system was analyzed. So far, around 50 articles have been published related to the effect of Se application on Cd uptake by plants. However, large differences between experimental conditions provided highly variable and sometimes contradictory results. In order to gain a more conclusive answer, we extracted data from these studies for a meta-analysis. We aimed to i) verify if there are significant interactions between $\mathrm{Cd}$ uptake and $\mathrm{Se}$ application in crops, ii) analyse to what extend Se can affect $\mathrm{Cd}$ concentrations in crops and iii) elucidate if the data support mechanisms proposed in the literature.

\section{Material and methods}

Literature data sourcing and extraction

An extensive analysis of the literature from 1970 to 2019 was used to identify studies that measured the effect of Se addition on Cd absorption by plants. The literature research was performed on Web of Science and Google Scholar using the following keywords: selenium, cadmium, plants, crops and interactions. In addition, the reference section of each paper identified in the search was scanned for additional, undetected, relevant papers. Both hydroponic and pot experiments were considered. Data of Cd concentration in the plants parts were extracted from tables and graphs using the online freeware WebPlotDigitizer and compiled (Supplementary Material 1). When Cd concentrations in plants could not be extracted, for instance only $3 \mathrm{D}$ graphs were given, and/or standard error or standard deviation was not reported, data were excluded. Total concentrations of $\mathrm{Cd}$ (natural + exogenous) but only $\mathrm{Se}$ concentration achieved by exogenous input of Se were used in the analysis. When $\mathrm{Cd}$ and Se concentrations could not be converted into $\mu \mathrm{mol} \mathrm{kg}{ }^{-1}$ of growth medium or soil, data were excluded. Hence, field studies and foliar application studies were not included. We partitioned the data into data subsets in order to make distinction between Se effect on the plant species, "rice only" and "rice excluded" data, plant organs roots and shoots, and Se species added, selenite $\left(\mathrm{SeO}_{3}\right)$ or selenate $\left(\mathrm{SeO}_{4}\right)$. Both plant organs and Se species subsets were again divided into "rice only" and "rice excluded" data subsets. In total 11 subsets where considered for the meta-analysis: full dataset, "rice only", "rice excluded", roots of "rice only", roots of "rice excluded", shoots "rice only", shoots of "rice excluded", $\mathrm{SeO}_{3}$ added to "rice only", $\mathrm{SeO}_{3}$ added to "rice excluded", $\mathrm{SeO}_{4}$ added to "rice only" and $\mathrm{SeO}_{4}$ added to "rice excluded".

Statistical analysis

We performed calculations and statistical analyses using the R open source software environment (version 3.5.0, $\mathrm{R}$ Core Team 2018) and functions available in the metafor package (version 2.0.0, Viechtbauer 2010). We used mean, standard deviation of Cd concentration, and sample size of treatments and the control (no Se added) to calculate a Response Ratio (log Response Ratio), used as effect size, and its variance. The response ratio is the log ratio of a control over a treatment calculated as (Hedges et al. 1999):

$R R=\log \left(\frac{C d_{c}}{C d_{t}}\right)$,

where $C d_{c}$ is the concentration of $\mathrm{Cd}$ in the control plant and $C d_{t}$ is the concentration of $\mathrm{Cd}$ in the treated plant.

The variance of $R R$ was calculated with:

$\operatorname{Var}(R R)=\frac{\sigma_{c}^{2}}{n_{c} \bar{x}_{c}^{2}}+\frac{\sigma_{t}^{2}}{n_{t} \bar{x}_{t}^{2}}$,

where $\sigma_{c}^{2}, n_{c}, \bar{x}_{c}^{2}$ are, respectively, the square of standard deviation for the control, the control sample size and the 
square of the average $C d_{c}$ and $\sigma_{t}^{2}, n_{t}, \bar{x}_{t}^{2}$ are, respectively, the square of standard deviation for the treatment, the treatment sample size and the square of the average $C d_{t}$.

A higher response ratio means a lower $\mathrm{Cd}$ concentration in the treated plant and therefore a higher effect of Se treatment on Cd mitigation. The effect size of the response ratio was plotted against Se treatments to visualize the relative change of $\mathrm{Cd}$ accumulation through Se additions.

Using the restricted maximum likelihood estimation (REML) in the function rma.mv(), we ran a metaregression model with random effect, with the log of Se concentration as moderator. We included a hierarchical random effect using article and individual observations in each model. Pseudo- $\mathrm{R}^{2}$ were calculated by computing the proportional reduction in the total variance. We ran separate metaregression models that included a single moderator for datasets presenting $\geq 10$ effect sizes calculated from $\geq 5$ different articles.

The publication bias was tested by modifying the metaregression models to include the variance of the effect size as a moderator. We considered analysis to be biased if the estimate of the slope of the variance differed from zero at $\alpha=0.1$. The heterogeneity was assessed using the Q-statistic within the data sets.

The full dataset (Supplementary Material 2), R code and output (Supplementary Material 3) used are available as supplementary information.

Inventory data and analysis

In addition to the meta-analysis, inventory data from the national monitoring program of Swedish arable soils and crops running since the 1990s (Eriksson et al. 1997, 2000, 2010) were included to test the outlined hypothesis. Sampling has been done every 10 years at the same location. In this evaluation, 280 soil and winter wheat samples from the latest sampling series were used. From each sampling point, nine plough layer samples (0-20 cm depth) were randomly taken with an auger within a radius of $3 \mathrm{~m}$, pooled, dried and sieved. From the same sampling area, four crop samples were taken using a frame of $0.25 \mathrm{~m}^{2}$. Cereal ears within each frame were cut with scissors, samples were pooled, dried, threshed for grains. For trace element analysis in soil and crop, samples were digested in $7 \mathrm{M} \mathrm{HNO}_{3}$ for $30 \mathrm{~min}$ and run on an ICP-SFMS. In this evaluation, total concentrations of $\mathrm{Se}$ and $\mathrm{Cd}$ were used.
As Se fertilization is not practiced in Sweden, only the impact of native Se in soil (natural Se variation) and its effect on $\mathrm{Cd}$ concentrations in grains was investigated. Total concentrations of $\mathrm{Cd}$ and $\mathrm{Se}$ in soils and crops were log-transformed to gain a normal distribution. Elemental concentrations in soil were transformed into a molar ratio of Se over $\mathrm{Cd}$ expressing the variation of $\mathrm{Se}$ relative to $\mathrm{Cd}$ in soil. Pearson correlations were conducted using the $\mathrm{R}$ open source software environment (version 3.5.0, R Core Team 2018) to determine the correlation coefficient and the significance of the correlation.

\section{Results}

Database and publication bias

Among the 51 articles (Supplementary Material 1) found presenting $\mathrm{Cd}$ concentration in plants with and without Se addition, 33 remained suitable for inclusion in our meta-analysis. From the articles retained, we calculated 325 effect sizes, which were separated into 11 datasets (Table 1). The experiments described in the articles were conducted on 16 different plant species and were published between 2008 and 2019. The range of Se added and Cd concentration in the growth media was between 1 and $600 \mu \mathrm{mol} \mathrm{kg}{ }^{-1}$ growth media for $\mathrm{Cd}$ and 0.1 to $255 \mu \mathrm{mol} \mathrm{kg}{ }^{-1}$ growth media for Se.

We detected publication bias in the dataset evaluating the effect of Se on Cd content of the roots of "rice only" $(P=0.0071)$. A significant amount of residual heterogeneity remained for all models $(p<0.01)$. All datasets, except the $\mathrm{SeO}_{4}$ for "rice only", had a sufficient number of articles and outcomes (using a cut-off rule of $\geq 5$ and $\geq 10$ respectively) to explore the potential relationship between $\mathrm{Se}$ addition and $\mathrm{Cd}$ concentration reduction. Therefore, data subsets discriminating roots and selenate for "rice only" were not analysed.

Quantification of the effect of Se application on Cd content in plants

The full dataset covered a large range of $\mathrm{Cd}$ and $\mathrm{Se}$ concentration in the growth media. Results of the metaregression model for the full dataset are shown in Fig. 1a. A significant linear positive effect of $\log \left(S e_{\text {added }}\right)$ on the effect size was found. The effect size increased with Se addition indicating a dose dependent 
Table 1 Characteristics of the data subsets of the meta-analysis, including the number of articles, outcomes and number of species derived from those articles, range of $\mathrm{Se}$ and $\mathrm{Cd}$ concentrations in the growth media. Results of significants models are presented.
Prediction of the model are showed as the concentration of Se to add, in $\mathrm{mg} \mathrm{Se} \mathrm{kg}^{-1}$ growth media, for Cd reduction of 10,25 and $50 \%$ in the crops

\begin{tabular}{|c|c|c|c|c|c|c|c|c|}
\hline \multirow[t]{2}{*}{ Data subset } & \multirow[t]{2}{*}{$\begin{array}{l}\text { No of } \\
\text { articles }\end{array}$} & \multirow[t]{2}{*}{$\begin{array}{l}\text { No data } \\
\text { outcome }\end{array}$} & \multirow[t]{2}{*}{$\begin{array}{l}\text { No } \\
\text { species }\end{array}$} & \multirow[t]{2}{*}{$\begin{array}{l}\text { Range }\left(\mathrm{Se}_{\text {Added }}\right) \\
\left(\mu \mathrm{mol} . \mathrm{kg}^{-1}\right)\end{array}$} & \multirow[t]{2}{*}{$\begin{array}{l}\text { Range }\left(\mathrm{Cd}_{\text {growth media }}\right) \\
\left(\mu \mathrm{mol} \cdot \mathrm{kg}^{-1}\right)\end{array}$} & \multicolumn{3}{|c|}{$\begin{array}{l}\text { Se addition (mg Se kg} \\
\text { for a } \mathrm{Cd} \text { reduction of }\end{array}$} \\
\hline & & & & & & $10 \%$ & $25 \%$ & $50 \%$ \\
\hline Complete dataset & 33 & 325 & 17 & $0.1-253$ & $1-600$ & 0.013 & 0.082 & 143 \\
\hline Shoots & 28 & 141 & 15 & $0.1-253$ & $1-600$ & 0.014 & 0.073 & 56 \\
\hline Roots & 25 & 92 & 12 & $0.1-253$ & $1-600$ & 0.071 & 0.25 & 35 \\
\hline Selenite & 26 & 264 & 15 & $0.1-253$ & $1-500$ & 0.010 & 0.057 & 53 \\
\hline Selenate & 9 & 57 & 6 & $0.1-63$ & $1-600$ & - & - & - \\
\hline Rice excluded & 22 & 168 & 16 & $0.1-253$ & $1-600$ & 0.057 & 0.28 & 149 \\
\hline Shoots & 18 & 93 & 14 & $0.1-253$ & $1-600$ & 0.077 & 0.35 & 147 \\
\hline Roots & 15 & 47 & 11 & $0.1-253$ & $1-600$ & 0.076 & 0.27 & 40 \\
\hline Selenite & 17 & 134 & 14 & $0.1-253$ & $1-500$ & 0.058 & 0.25 & 85 \\
\hline Selenate & 5 & 32 & 5 & $2-20$ & $10-600$ & - & - & - \\
\hline Rice only & 11 & 157 & 1 & $0.1-63$ & $1-53$ & - & - & - \\
\hline Shoots & 6 & 48 & 1 & $1.1-63$ & $3.7-53$ & - & - & - \\
\hline Roots & 10 & 45 & 1 & $1.1-63$ & $6-53$ & - & - & - \\
\hline Selenite & 9 & 130 & 1 & $0.1-63$ & $1-53$ & - & - & - \\
\hline Selenate & 4 & 25 & 1 & $0.1-63$ & $1-15$ & - & - & - \\
\hline Rice only (pot exp) & 6 & 119 & 1 & $1.3-63$ & $3.7-37$ & - & - & - \\
\hline Shoots & 6 & 37 & 1 & $1.3-63$ & $3.7-37$ & 0.13 & 0.28 & 7.7 \\
\hline Roots & 6 & 36 & 1 & $1.3-63$ & $6-37$ & - & - & - \\
\hline Selenite & 6 & 105 & 1 & $1.3-63$ & $3.7-37$ & - & - & - \\
\hline Selenate & 2 & 14 & 1 & $1.3-63$ & $13-16$ & - & - & - \\
\hline
\end{tabular}

decrease of Cd concentrations in plants when Se was added to the growth media. The model intercept, corresponding to a zero-effect of added Se when $\log \left(S e_{\text {added }}\right)$ equals zero, or equivalently $S e_{\text {added }}=1$. In the present case, the intercept showed that for an addition of $1 \mu \mathrm{mol}$ Se $\mathrm{kg}^{-1}$ growth media, corresponding to $0.08 \mathrm{mg} \mathrm{Se}$ $\mathrm{kg}^{-1}$ of growth media, the expected effect size was 0.22 corresponding to a $19.7 \% \mathrm{Cd}$ reduction in crops.

According to the model, the regression slope resembles the effect size of the increase of $\log \left(S e_{\text {added }}\right)$. The effect size increased by 0.063 per one unit of $\log \left(S e_{\text {added }}\right)$. Calculated pseudo- $\mathrm{R}^{2}$ values were low (0.03), highlighting a high variability of the data. Still, the significance of the model indicated that despite low fit to the model, a significant trend of the effect of Se addition on $\mathrm{Cd}$ reduction in plants was present. In concrete numbers, the model predicts a decrease of $\mathrm{Cd}$ concentration in crops of 10,25 and $50 \%$ by the addition of $0.013,0.082$ and $142 \mathrm{mg} \mathrm{Se}$ $\mathrm{kg}^{-1}$ of growth media, respectively (Table 1 ).

Fig. 1 Effect size in function of the concentration of Se added to the growth media (log-transformed) for the complete dataset (a), "rice only" pot experiments (b), "rice excluded data (c). The size of the dots represent the variance of the effect size, the colour the concentration of Cd in the growth media (in $\mu \mathrm{mol} \mathrm{kg}{ }^{-1}$ ). The lines represent the prediction from the metaregression model (plain line) with the $95 \%$ confidence interval (dotted lines). n: number of data points. Significance of the model: ns; $* ; * ; * * *=$ not significant; significant at $P<0.05 ; 0.01$ or 0.001 respectively. The top and right scales shown on figure a) represent the values of the concentration of Se added, not log-transformed and the equivalent of the effect size in percentage of $\mathrm{Cd}$ concentration reduction, respectively 


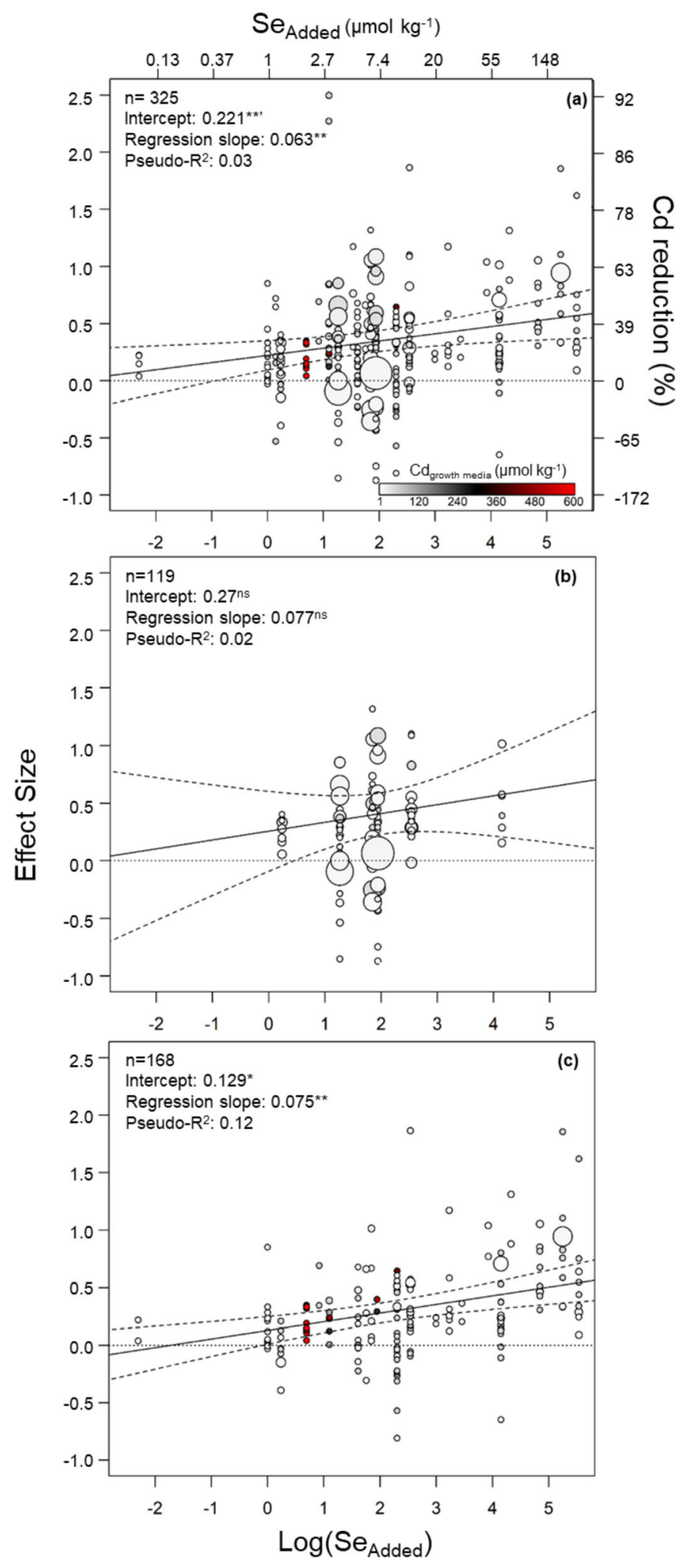


Elucidation of possible mechanisms

In order to identify possible mechanisms causing the observed Se effect, subsets of data were extracted. In our case, data for redox conditions, speciation of Se and reduction of $\mathrm{Cd}$ concentration in roots and shoots were analysed in further detail.

\section{Effect of soil redox conditions}

In this subset, plants grown under anoxic conditions, "rice only", were separated from plants grown under aerobic soil conditions, "rice excluded", in order to highlight if Se acts differently under reducing and oxidizing conditions in the growth medium. However, only waterlogged pot experiments were considered for the "rice only" data (6 articles, 119 data points). There was no information given about the oxygen status of rice grown in hydroponic solutions and the data were excluded. In the pot experiments it was specified that rice was grown under flooded conditions, where the redox potential quickly drop under $0 \mathrm{mv}$ and can reach $-200 \mathrm{mV}$ (Affholder et al. 2017). Results for "rice only" (low redox and anoxic conditions, Fig. 1b) showed no significant relationship between Se added and Cd reduction in plants. The model intercept of 0.26 was not significant showing that Se addition had no significant effect on the $\mathrm{Cd}$ reduction in rice grown under paddy conditions. Still, there was a tendency that Se also affected $\mathrm{Cd}$ in rice.

Results from the data subset excluding rice (aerobic soil conditions, Fig. 1c) showed a significant linear correlation between Se addition and the effect size and improved the fit of data (pseudo $\mathrm{R}^{2}=0.12$ ). An effect size of 0.075 per unit of $\log \left(S e_{\text {added }}\right)$ was found, i.e., addition of $0.06,0.28$ and $149 \mathrm{mg} \mathrm{Se} \mathrm{kg}^{-1}$ growth media would reduce $\mathrm{Cd}$ concentration by 10,25 and $50 \%$, respectively (Table 1). The intercept was also significant, therefore for addition of $1 \mu \mathrm{mol} \mathrm{Se} \mathrm{kg}{ }^{-1}$ growth media, corresponding to $0.08 \mathrm{mg} \mathrm{Se} \mathrm{kg}{ }^{-1}$ of growth media, had an effect size of 0.12 equivalent to $12.1 \%$ reduction of $\mathrm{Cd}$ in crops.

\section{Effect of selenium species added}

The results of the model separating selenate $\left(\mathrm{SeO}_{4}{ }^{2-}\right)$ and selenite $\left(\mathrm{SeO}_{3}{ }^{2-}\right)$ additions on $\mathrm{Cd}$ uptake by crops, for the "rice excluded" dataset, are presented in Fig. 2. Data for "rice only" are not shown as the number of articles using $\mathrm{SeO}_{4}$ was insufficient (Table 1). Addition of selenate to crops excluding rice had no significant effect on the effect size, neither the intercept nor the slope of the model were significant (Fig. 2a). In contrary, selenite addition caused a significant linear response (Fig. 2b) with an increase of the effect size of 0.081 per unit of $\log \left(S e_{\text {added }}\right)$. Excluding the selenate data increased the fit of the "rice excluded" data to the model (pseudo- $\mathrm{R}^{2}=0.16$ ).

\section{Effect of selenium on Cd content in roots and shoots}

Figure 3 illustrates to what extent roots (Fig. 3a) and shoots (Fig. 3b) were affected by Se addition using the "rice excluded" dataset. Results for the "rice only" dataset were shown for shoots only (Fig. 3c) as there is a bias for the roots data subset (see 3.1. Database and publication bias). Crop data excluding rice showed a significant linear response of Se on Cd reduction in both roots and shoots with the best fit for roots (pseudo- $\mathrm{R}^{2}=$ 0.25 ) followed by shoots (pseudo- $R^{2}=0.19$ ). The model predicted an increase of the effect size of 0.094 and 0.078 per unit of $\log \left(\mathrm{Se}_{\mathrm{added}}\right)$ for roots and shoots, respectively. Basically, 0.08, 0.27 and $40 \mathrm{mg} \mathrm{Se} \mathrm{kg}{ }^{-1}$ growth media reduced $\mathrm{Cd}$ by 10,25 and $50 \%$ in roots and $0.08,0.35$ and $147 \mathrm{mg} \mathrm{Se} \mathrm{kg}^{-1}$ growth media reduced $\mathrm{Cd}$ in shoots to the same extent (Table 1).

Shoot data of "rice only" were also significantly affected (pseudo $\mathrm{R}^{2}=0.15$ ) by Se addition (Fig. $3 \mathrm{~d}$ ). The model predicted an increase of the effect size of 0.14 per unit of $\log \left(\mathrm{Se}_{\text {added }}\right)$, which means that addition of $0.12,0.29$ and $7.7 \mathrm{mg} \mathrm{Se} \mathrm{kg}{ }^{-1}$ growth media would reduce Cd by 10,25 and $50 \%$ in rice shoots (Table 1).

Inventory analysis

In Swedish arable soils, concentrations of native Se and Cd were positively correlated $(\mathrm{R}=0.43, P<0.0001$, Pearson's correlation), Fig. 4a. Contents resembled the linked occurrence in sedimentary rocks from which soils were formed. Contamination of soils with Cd through P fertilizers (Roberts 2014) had a minor impact. Legacy $\mathrm{Cd}$ from $\mathrm{P}$ fertilization in soil was negligible as mineral $\mathrm{P}$ fertilizers low in $\mathrm{Cd}\left(<1 \mathrm{mg} \mathrm{Cd} \mathrm{kg}^{-1} \mathrm{P}\right)$ have been used in Sweden since the end of the 80s. Considering that Se and Cd were natively associated in soil, relative variations between elements were obtained using molar ratios of Se over $\mathrm{Cd}$. Plotting $\mathrm{Cd}$ concentrations in wheat grain against molar ratios showed a significant 

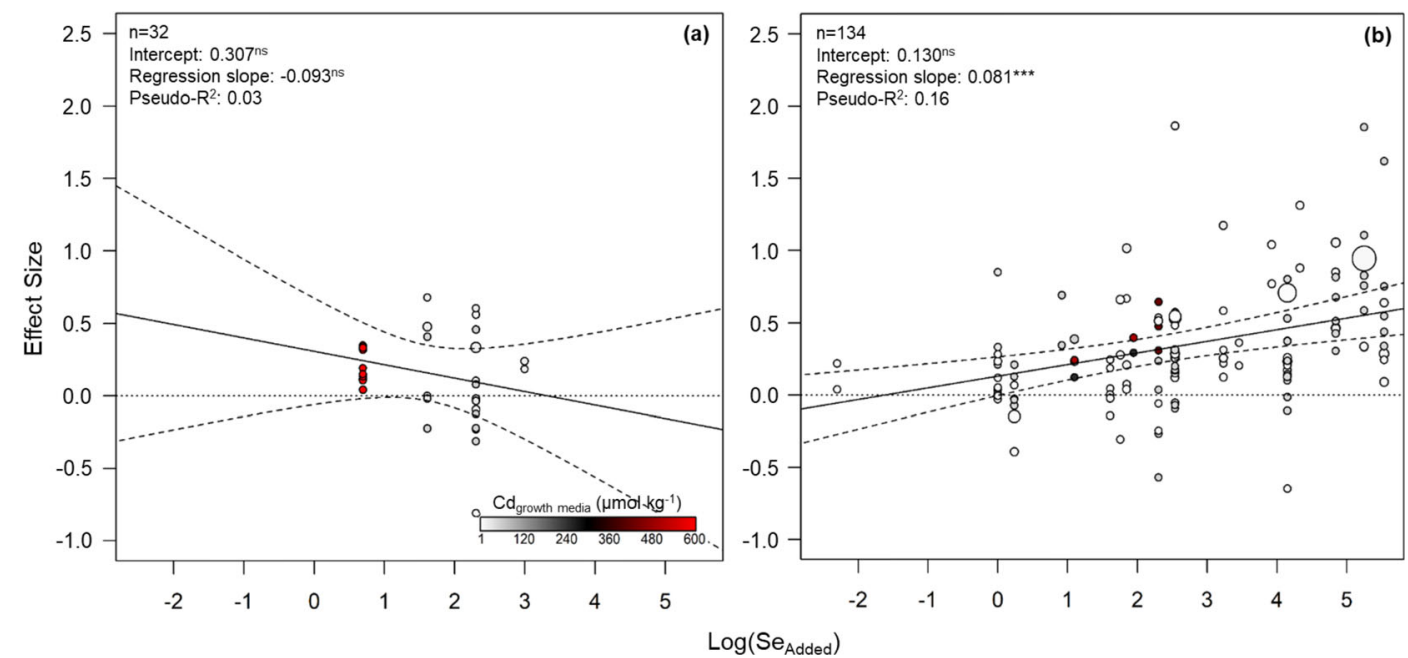

Fig. 2 Effect size in function of the concentration of selenium added to the growth media (logarithm transformed). Results of the "rice excluded" dataset for the addition of selenate (a) and selenite (b). The size of the dots represent the variance of the effect size. The colour of the dots represent the concentration $\mathrm{Cd}$ in the growth media. The lines represent the prediction from the metaregression

negative relationship $(\mathrm{R}=-0.22, P<0.001$, Pearson's correlation), Fig. 4b. Again, this was interpreted as an indication for the possible reduction of $\mathrm{Cd}$ in crops even by native $\mathrm{Se}$ in soil.

\section{Discussion}

Results of the meta-analysis performed on the whole dataset (Fig. 1a) indicated a significant, dose dependent effect of Se on reduction of $\mathrm{Cd}$ concentration in plants. The relatively poor fits of the data to the model (pseudo$\mathrm{R}^{2}$ ) were explained by the large difference in experimental conditions (different plant species and varieties, growing period, soils, etc.) of the 33 studies that matched the selection criteria. A low $R^{2}$ is not invalidating the conclusion, but precision of predictions varied widely. Similarly, inventory data of $\mathrm{Cd}$ and $\mathrm{Se}$ concentrations in soil and wheat grains from samples all over Sweden (Fig. 4) supported the outcome of the meta-analysis. Higher concentration of native Se over native $\mathrm{Cd}$ in soil lowered concentrations of $\mathrm{Cd}$ in wheat grains. Although evidence of the effect of $\mathrm{Se}$ on $\mathrm{Cd}$ uptake by crops was shown, mechanisms are still not well understood. We outline potential mechanisms found in the literature (Fig. 5) that could be involved in $\mathrm{Cd}$ and Se interaction in soil and crop in the following discussion. model (plain line) with the $95 \%$ confidence interval (dotted lines). $\mathrm{n}$ : number of data points. Significance of the model: ns; *; **; $* * *=$ not significant; significant at $P<0.05 ; 0.01$ or 0.001 respectively. For an idea of the equivalent of the scale in concentration of Se non log-transform and percent of $\mathrm{Cd}$ reduction see Fig. 1a

One reaction proposed is the formation of nonbioavailable cadmium selenide (CdSe) in soil first mentioned by Shanker et al. (1995). However, so far, no evidence for the formation of this compound in soil has been published. According to Gustafsson (2013), a nonbioavailable Cd-Se phase would only be stable at redox potentials lower than $100 \mathrm{mV}$, requiring reduction to elemental selenium and then to selenide (Fig. 5). Such reactions may occur under anoxic conditions in paddy soils, where redox potential values can drop up to $-200 \mathrm{mV}$ during flooding. However, such low redox potentials do not permanently exist in non-waterlogged arable top-soils (Husson 2013). By separating the data treating rice grown in flooded soil ("rice only") separately from other species ("rice excluded"), we distinguished between low and high redox levels in soils. In case of non-bioavailable cadmium selenide being formed, a dose dependent decrease of plant available $\mathrm{Cd}$ would be expected. The results highlighted a dose dependent effect of Se on mitigation of Cd concentration for non-rice crop data ("rice excluded"). "Rice only" data showed a tendency of a positive effect but this was not significant. A wider range of Se additions to rice grown under anoxic conditions would be needed to confirm or reject this mechanism. However, knowing from the geochemistry of Se that selenide becomes a major species at low redox conditions and that selenide can substitute S in iron sulphide (Hatten Howard 1977), 


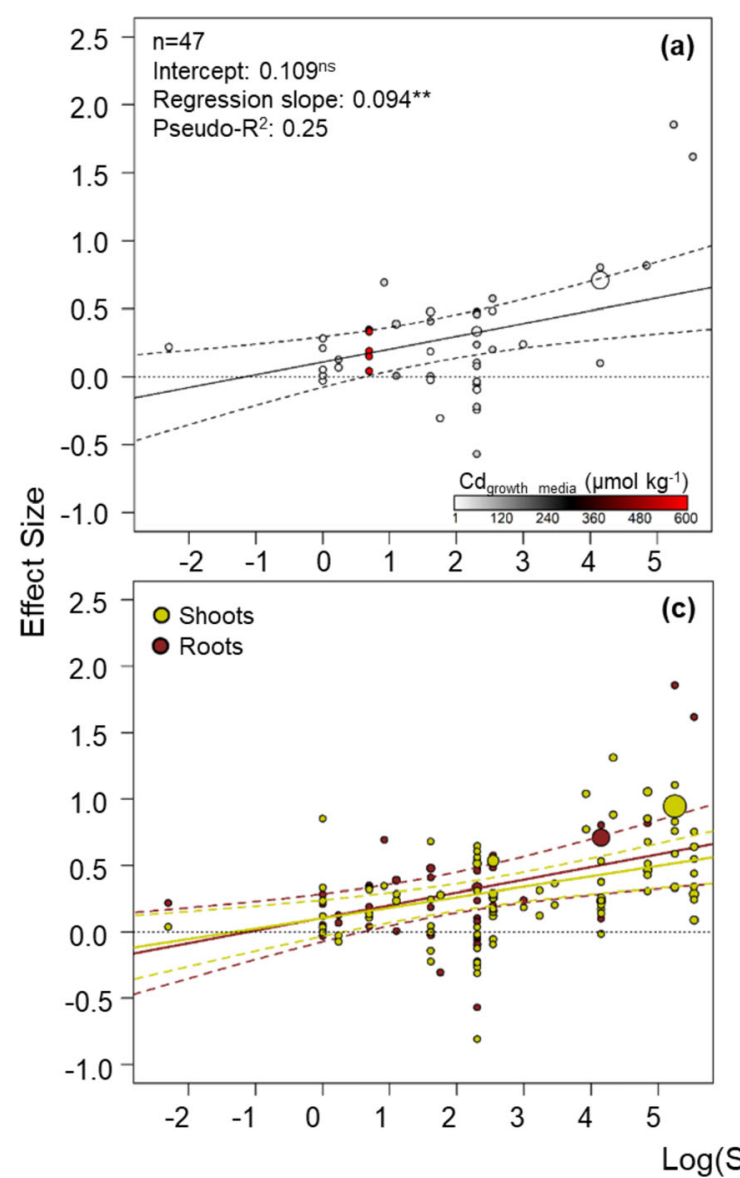

Fig. 3 Effect size in function of the concentration of selenium added to the growth media (logarithm transformed). Data for the roots (a) and shoots (b) for the "rice excluded" data subset, comparison of both (c) and data for the shoots of the "rice only" (pot experiment) data subset (d). The colour of the dots represent the concentration of $\mathrm{Cd}$ in the growth media. The lines represent

it was likely that iron selenide was formed whereby concentration of soluble selenium become very low (Masscheleyn et al. 1990). Iron bonding of Se in an environment with excess iron may explain why no dose dependent response of Se addition was observed in the "rice only" data. In addition, another iron-related mechanism, formation of iron plaques around roots of rice and wetland plants may also act as a barrier against uptake of $\mathrm{Cu}, \mathrm{Ni}, \mathrm{Mn}$, and $\mathrm{Cd}$ (Taylor and Crowder 1983; Otte et al. 1989; Greipsson 1994; Ye et al. 1998; Wang and Peverly 1999). Recent studies suggested that the adsorption capacity of iron plaque around rice roots increased when Se was added, resulting in an increased sequestration of Cd (Huang et al. 2017) and Hg (Zhou and Li 2018). Thus, greater metal sequestration in iron plaques by Se may affect $\mathrm{Cd}$ absorption by roots and

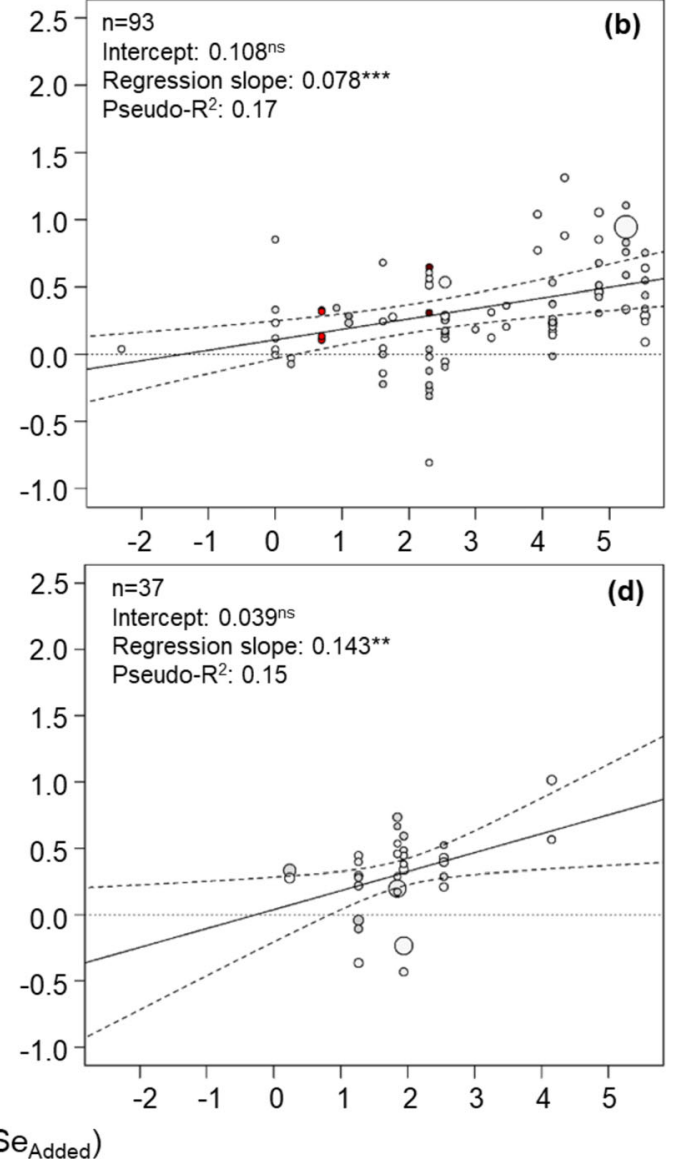

the prediction from the metaregression model (plain line) with the 95\% confidence interval (dotted lines). n: number of data points. Significance of the model: ns; $* * * ; * * *=$ not significant; significant at $P<0.05 ; 0.01$ or 0.001 respectively. For an idea of the equivalent of the scale in concentration of Se non log-transform and percent of $\mathrm{Cd}$ reduction see Fig. 1a

may explain the tendency observed of a non-dose dependent reduction of $\mathrm{Cd}$. Unfortunately, there was no information available about the iron content of the soils in the studies.

For "rice excluded" data, a dose dependent effect of $\mathrm{Cd}$ mitigation was observed (Fig. 1c). suggesting involvement of non-mobile cadmium selenide. However, chemical reduction of selenate/selenite to elemental $\mathrm{Se}$ is thermodynamically only favoured under anaerobic conditions (Masscheleyn et al. 1990) but other mechanisms making $\mathrm{Cd}$ less bioavailable can be involved. Biological reduction through bacteria reducing selenate (Se(VI)) and selenite (Se(IV)) into elemental selenium $\left(\mathrm{Se}^{0}\right)$ and selenide ( $\left.\mathrm{Se}(-\mathrm{II})\right)$ has been found (Nancharaiah and Lens 2015). Selenite was more easily reduced than selenate (Doran 1982). This would be 


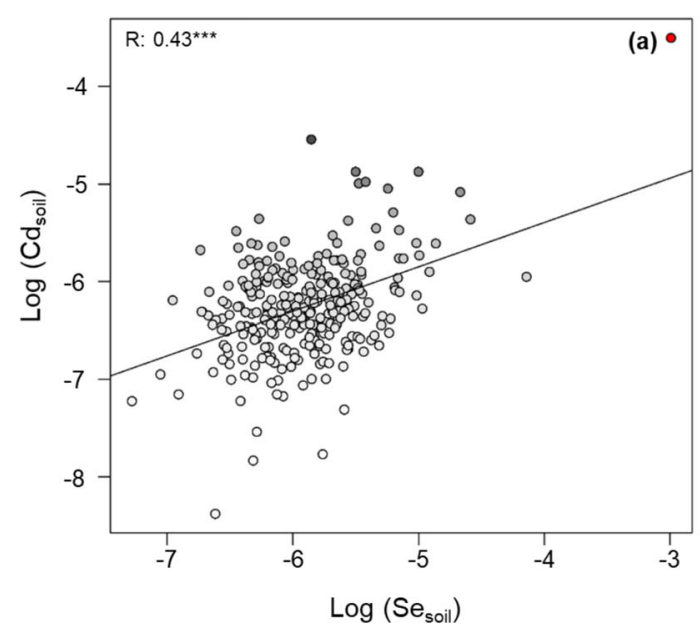

Fig. 4 Cd concentration in function of Se concentration in Swedish soils (a), Cd concentration in wheat grains in function of the ratio of Se concentration over Cd concentrations in Swedish soils

consistent with observations presented in the literature showing that selenite was more effective to reduce $\mathrm{Cd}$ concentration in plants than selenate (Shanker et al. 1995, 1996; Zhou et al. 2017; Yu et al. 2018). However, we were unable to confirm these observations, which would have required a wider range of selenate concentrations.

Recently, microbial formation of CdSe quantum dots was shown (Kumar et al. 2007; Cui et al. 2009) and a Pseudomonas sp. strain showing this ability was isolated from soil samples (Ayano et al. 2014). Gomez Ojeda et al. (2013) suggested that $\mathrm{Cd}$ and Se can interact in plants and form a poorly soluble compounds, which could be CdSe quantum dots. More evidence that a

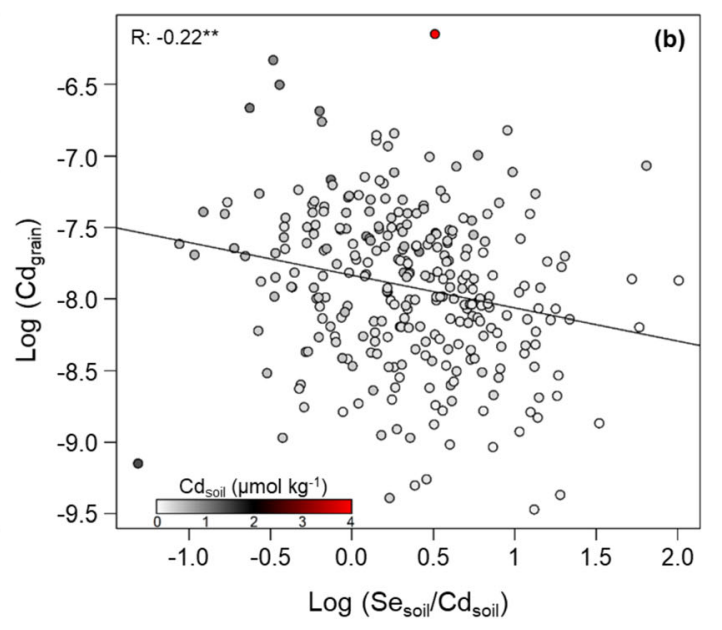

(all data $\log$ transformed). $n=280$, R: Pearson correlation coefficient, significance of the correlation: ns; *; **; *** = not significant; significant at $P<0.05 ; 0.01$ or 0.001 respectively

Cd-Se interaction can be located in the plant was suggested by other studies showing a Cd reduction when Se was applied on leaves (Wang et al. 2013; Abd Allah et al. 2016; Liao et al. 2016; Ahmad et al. 2016; Chi et al. 2017) or roots were treated with Se before $\mathrm{Cd}$ exposure (Lin et al. 2012; Saidi et al. 2014; Mozafariyan et al. 2014).

Plants have several detoxification mechanisms. The main strategies used by plants to tolerate and minimize detrimental effects of high metal concentrations are to restrict uptake, limit translocation or detoxify through chelation and subcellular compartmentalization to avoid accumulation in the whole plant (Jan and Parray 2016). Root related mechanisms, which may contribute to the

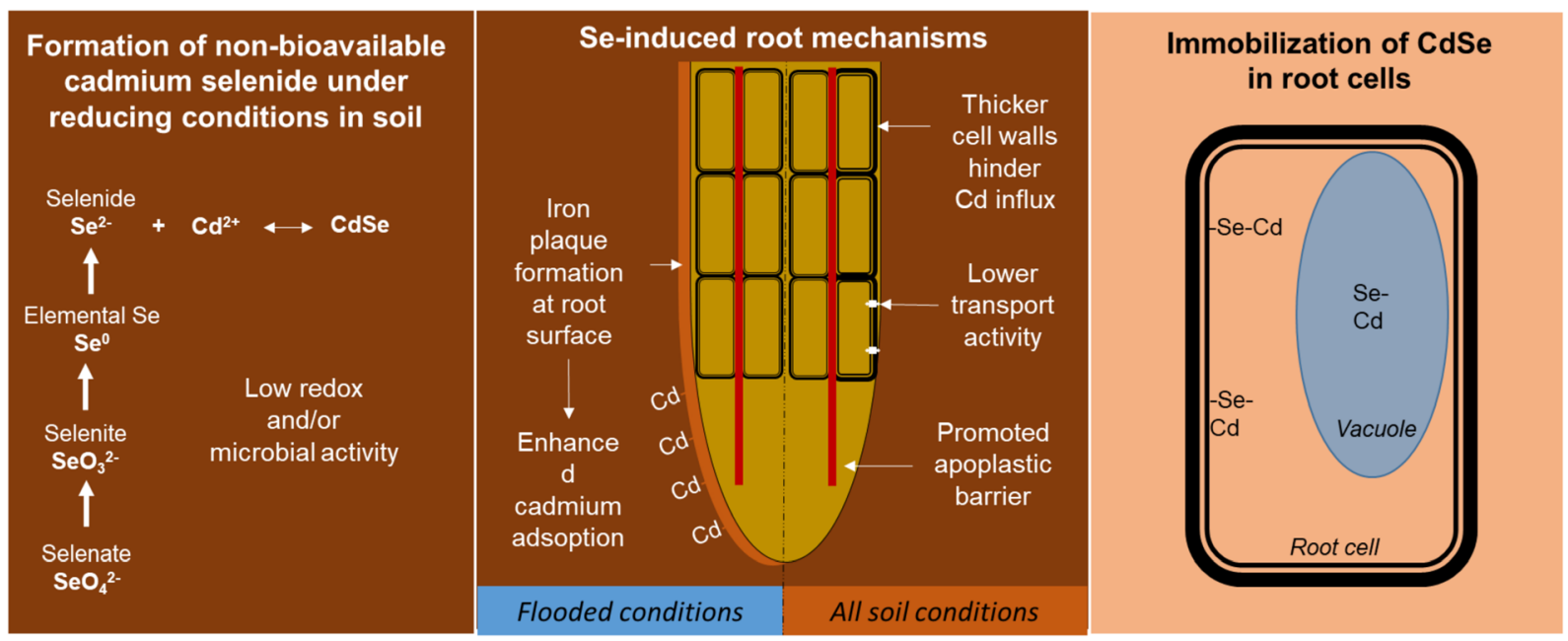

Fig. 5 Explanatory diagram of the potential processes involved in the Cd-Se interactions in soil and crops according to the literature 
Cd reduction uptake, could be an enhanced development of apoplastic barriers in the endodermis of roots and a lower activity of the membrane transporters activity (Wang et al. 2014). Moreover, more lignin and thicker cell walls may be formed in cells being exposed to Se (Cui et al. 2018) and therefore restrict the translocation of $\mathrm{Cd}$ that will be adsorbed. A further mechanism can be restriction of $\mathrm{Cd}$ translocation by compartmentalization. Gomez Ojeda et al. (2013) found an increase of $\mathrm{Cd}$ in poorly soluble cell fractions upon Se addition. One would expect that compartmentalization of $\mathrm{Cd}$ in root cells would reduce $\mathrm{Cd}$ translocation and therefore lead to greater $\mathrm{Cd}$ reduction in the shoots than in the roots. However, results for shoots and roots for the data "rice excluded" did not show any evidence of compartmentalization. Cadmium reduction in roots and shoots increased both linearly and significantly with Se addition in the growth medium (Fig. 4a and b). Comparison of both models (Fig. 4c) highlighted that Cd reduction in roots and shoots were similar. This would suggest that the main mechanism involved would be a restricted uptake of $\mathrm{Cd}$ by roots, which would be possible either by reduction of the bioavailability of $\mathrm{Cd}$ in the soil or reduced absorption by roots.

Concerning "rice only", we cannot conclude about a mechanism in the crop (Fig. 4d) as a larger data set would be required to verify different hypotheses.

\section{Conclusions and perspective}

The aim of this paper was to identify if there are significant interactions between $\mathrm{Se}$ and $\mathrm{Cd}$ in the soil-crop system which may reduce $\mathrm{Cd}$ uptake by plants.

The impact of Se addition on Cd reduction in plants was found to be significant and dose-dependent including all crops, different selenium compounds, and different plant organs in the analysis. Excluding rice from the data (aerobic soil conditions only) resulted in a more pronounced effect with higher significance. Analyzing all plant organs of rice (anaerobic soil conditions only) showed that there was a tendency but no dosedependent reduction of $\mathrm{Cd}$ by Se. Treating rice shoots separately showed that there was dose-dependent and significant effect of Se addition. The results implied that a Cd-Se compound may be formed presupposing reducing conditions locally in microsites of the soil or at the root surface. More investigations are needed to fully understand possible mechanisms involved.
Acknowledgements The authors would like to thank Dr. J.E. Eriksson from the Swedish Agricultural University for sharing the inventory data from the national monitoring program of Swedish arable soils and crops. Affholder MC held a post-doctoral fellowship funded by the Faculty of Natural Resources and Agricultural Sciences from the Swedish University of Agricultural Sciences (SLU).

Open Access This article is distributed under the terms of the Creative Commons Attribution 4.0 International License (http:// creativecommons.org/licenses/by/4.0/), which permits unrestricted use, distribution, and reproduction in any medium, provided you give appropriate credit to the original author(s) and the source, provide a link to the Creative Commons license, and indicate if changes were made.

\section{References}

Abd Allah EF, Hashem A, Alqarawi AA (2016) Mitigation of cadmium induced stress in tomato (Solanum lycopersicum L.) by selenium. Pak J Bot 48:953-961

Affholder MC, Weiss DJ, Wissuwa M, Johnson-Beebout SE, Kirk GJD (2017) Soil $\mathrm{CO}_{2}$ venting as one of the mechanisms for tolerance of $\mathrm{Zn}$ deficiency by rice in flooded soils. Plant Cell Environ 40:3018-3030. https://doi. org/10.1111/pce.13069

Ahmad P, Abd Allah EF, Hashem A, Sarwat M, Gucel S (2016) Exogenous application of selenium mitigates cadmium toxicity in Brassica juncea L. (Czern \& Cross) by up-regulating antioxidative system and secondary metabolites. J Plant Growth Regul 35:936-950. https://doi.org/10.1007/s00344-016-9592-3

Ayano H, Miyake M, Terasawa K, Kuroda M, Soda S, Sakaguchi T, Ike M (2014) Isolation of a selenite-reducing and cadmium-resistant bacterium Pseudomonas sp. strain RB for microbial synthesis of CdSe nanoparticles. J Biosci Bioeng 117:576-581. https://doi.org/10.1016/j. jbiosc.2013.10.010

Chi SL, Xu WH, Liu J, Wang WZ, Xiong ZT (2017) Effect of exogenous selenium on activities of antioxidant enzymes, cadmium accumulation and chemical forms of cadmium in tomatoes. Int J Agric Biol 19:1615-1622. https://doi. org/10.17957/IJAB/15.0478

Combs GF (2001) Selenium in global food systems. Br J Nutr 85: 517-547. https://doi.org/10.1079/BJN2000280

Cui R, Liu H-H, Xie H-Y, Zhang Z-L, Yang Y-R, Pang D-W, Xie Z-X, Chen B-B, Hu B, Shen P (2009) Living yeast cells as a controllable biosynthesizer for fluorescent quantum dots. Adv Funct Mater 19:2359-2364. https://doi.org/10.1002 /adfm.200801492

Cui J, Liu T, Li Y, Li F (2018) Selenium reduces cadmium uptake into rice suspension cells by regulating the expression of lignin synthesis and cadmium-related genes. Sci Total Environ 644:602-610. https://doi.org/10.1016/j. scitotenv.2018.07.002

Doran JW (1982) Microorganisms and the biological cycling of selenium. In: Marshall KC (ed) Advances in microbial ecology, vol 6. Springer US, Boston, pp 1-32 
EFSA (2014) Scientific opinion on dietary reference values for selenium. EFSA J 12:3846

EFSA (2017) Dietary reference values for nutrients: summary report. EFSA supporting publication 2017:e15121

EFSA, European Food Safety Authority (2009) Cadmium in food - scientific opinion of the panel on contaminants in the food chain. EFSA J 980:1-139

Eriksson JE, Andersson A, Andersson R (1997) Current status of Swedish arable soils. Report 4778. Swedish Environmental Protection Agency, Stockholm

Eriksson JE, Stenberg B, Andersson A, Andersson R (2000) Current status of Swedish arable soils and crops. Report 5062. Swedish Environmental Protection Agency, Stockholm

Eriksson J, Mattsson L, Söderström M (2010) Tillståndet i svensk åkermark och gröda. Data från 2001-2007. Report 6349. Swedish Environmental Protection Agency, Stockholm

Fordyce F (2007) Selenium geochemistry and health. Ambio 36: 94-97

Gomez Ojeda A, Corrales Escobosa AR, Wrobel K, Yanez Barrientos E, Wrobel K (2013) Effect of Cd(ii) and Se(iv) exposure on cellular distribution of both elements and concentration levels of glyoxal and methylglyoxal in Lepidium sativum. Metallomics 5:1254-1261. https://doi.org/10.1039 /C3MT00058C

Greipsson S (1994) Effects of iron plaque on roots of rice on growth and metal concentration of seeds and plant tissues when cultivated in excess copper. Commun Soil Sci Plant Anal 25:2761-2769. https://doi.org/10.1080 /00103629409369223

Gustafsson J (2013) Soil chemical behaviour of cadmium pigments from paints. PM 4/13. Swedish Chemical Agency, Stockholm

Hatten Howard J (1977) Geochemistry of selenium: formation of ferroselite and selenium behavior in the vicinity of oxidizing sulfide and uranium deposits. Geochim Cosmochim Acta 41: 1665-1678. https://doi.org/10.1016/0016-7037(77)90176-4

Hedges LV, Gurevitch J, Curtis PS (1999) The meta-analysis of response ratios in experimental ecology. Ecol 80:1150-1156. https://doi.org/10.2307/177062

Huang G, Ding C, Guo F, Li X, Zhang T, Wang X (2017) Underlying mechanisms and effects of hydrated lime and selenium application on cadmium uptake by rice (Oryza sativa L.) seedlings. Environ Sci Pollut Res 24:1892618935. https://doi.org/10.1007/s11356-017-9573-5

Husson O (2013) Redox potential (eh) and pH as drivers of soil/plant/microorganism systems: a transdisciplinary overview pointing to integrative opportunities for agronomy. Plant Soil 362:389-417. https://doi.org/10.1007/s11104012-1429-7

IARC, International Agency for Research on Cancer (1993) Beryllium, cadmium, mercury and exposures in the glass manufacturing industry. IARC monographs on the evaluation of carcinogenic risk of chemicals to humans, vol 58. Lyon, France. 444 pp. http://monographs.iarc. fr/ENG/Monographs/vol58/volume58.pdf

Jan S, Parray JA (2016) Approaches to heavy metal tolerance in plants, 1 st edn. Springer Nature, Singapore

Jones GD, Droz B, Greve P, Gottschalk P, Poffet D, McGrath SP, Seneviratne SI, Smith P, Winkel LHE (2017) Selenium deficiency risk predicted to increase under future climate change.
Proc Natl Acad Sci 114:2848-2853. https://doi.org/10.1073 /pnas.1611576114

Kumar SA, Ansary AA, Ahmad A, Khan MI (2007) Extracellular biosynthesis of CdSe quantum dots by the fungus, Fusarium oxysporum. J Biomed Nanotechnol 3:190-194. https://doi. org/10.1166/jbn.2007.027

Liao G, Wu Q, Feng R, Guo J, Wang R, Xu Y, Ding Y, Fan Z, Mo L (2016) Efficiency evaluation for remediating paddy soil contaminated with cadmium and arsenic using water management, variety screening and foliage dressing technologies. J Environ Manag 170:116-122. https://doi.org/10.1016/j. jenvman.2016.01.008

Lin L, Zhou W, Dai H, Cao F, Zhang G, Wu F (2012) Selenium reduces cadmium uptake and mitigates cadmium toxicity in rice. J Hazard Mater 235:343-351. https://doi.org/10.1016/j. jhazmat.2012.08.012

Masscheleyn PH, Delaune RD, Patrick WH (1990) Transformations of selenium as affected by sediment oxidation-reduction potential and $\mathrm{pH}$. Environ Sci Technol 24:91-96. https://doi.org/10.1021/es00071a010

Mozafariyan M, Shekari L, Hawrylak-Nowak B, Kamelmanesh MM (2014) Protective role of selenium on pepper exposed to cadmium stress during reproductive stage. Biol Trace Elem Res 160:97-107. https://doi.org/10.1007/s12011-014-00282

Nancharaiah YV, Lens PNL (2015) Ecology and biotechnology of selenium-respiring bacteria. Microbiol Mol Biol Rev 79:6180. https://doi.org/10.1128/MMBR.00037-14

Otte ML, Rozema J, Koster L, Haarsma MS, Broekman RA (1989) Iron plaque on roots of Aster tripolium L.: interaction with zinc uptake. New Phytol 111:309-317. https://doi. org/10.1111/j.1469-8137.1989.tb00694.x

R Core Team (2018) R: a language and environment for statistical computing. $\mathrm{R}$ foundation for statistical computing, Vienna

Rayman MP (2012) Selenium and human health. Lancet 379: 1256-1268. https://doi.org/10.1016/S0140-6736(11)614529

Rizwan M, Ali S, Abbas T, Zia-ur-Rehman M, Hannan F, Keller C, Al-Wabel MI, Ok YS (2016) Cadmium minimization in wheat: a critical review. Ecotoxicol Environ Saf 130:43-53. https://doi.org/10.1016/j.ecoenv.2016.04.001

Roberts TL (2014) Cadmium and phosphorous fertilizers: the issues and the science. SYMPHOS 2013 - 2nd Int Symp Innov Technol Phosphate Ind 83:52-59. https://doi. org/10.1016/j.proeng.2014.09.012

Saidi I, Chtourou Y, Djebali W (2014) Selenium alleviates cadmium toxicity by preventing oxidative stress in sunflower (Helianthus annuus) seedlings. J Plant Physiol 171:85-91. https://doi.org/10.1016/j.jplph.2013.09.024

Salonen JT, Alfthan G, Huttunen J, Pikkaraien J, Puska P (1982) Association between cardiovascular death and myocardial infarction and serum selenium in a matched-pair longitudinal study. Lancet 320:175-179. https://doi.org/10.1016/S01406736(82)91028-5

Schwarz K, Foltz CM (1957) Selenium as an integral part of factor 3 against dietary necrotic liver degeneration. J Am Chem Soc 79:3292-3293. https://doi.org/10.1021/ja01569a087

Shanker K, Mishra S, Srivastava S, Srivastava R, Dass S, Prakash S, Srivastava MM (1995) Effect of selenite and selenate on plant uptake of cadmium by kidney bean (Phaseolus mungo) with reference to $\mathrm{Cd}-\mathrm{Se}$ interaction. Chem Speciat 
Bioavailab 7:97-100. https://doi.org/10.1080 /09542299.1995.11083251

Shanker K, Mishra S, Srivastava S (1996) Effect of selenite and selenate on plant uptake of cadmium by maize (Zea mays). Bull Environ Contam Toxicol 56:419-424. https://doi. org/10.1007/s001289900060

Söderström M, Eriksson J (2013) Gamma-ray spectrometry and geological maps as tools for cadmium risk assessment in arable soils. Geoderma 192:323-334. https://doi. org/10.1016/j.geoderma.2012.07.014

Taylor GJ, Crowder AA (1983) Uptake and accumulation of heavy metals by Typha latifolia in wetlands of the Sudbury, Ontario region. Can J Bot 61:63-73. https://doi.org/10.1139/b83-005

Viechtbauer W (2010) Conducting meta-analyses in R with the metafor package. J Stat Softw 36:1-48

Wang T, Peverly JH (1999) Iron oxidation states on root surfaces of a wetland plant (Phragmites australis). Soil Sci Soc Am J 63:24 7-252. https://doi.org/10.2136 /sssaj1999.03615995006300010036x

Wang J, Wang Z, Mao H, Zhao H, Huang D (2013) Increasing Se concentration in maize grain with soil- or foliar-applied selenite on the Loess Plateau in China. Field Crop Res 150:8390. https://doi.org/10.1016/j.fcr.2013.06.010

Wang X, Tam NF-Y, Fu S, Ametkhan A, Ouyang Y, Ye Z (2014) Selenium addition alters mercury uptake, bioavailability in the rhizosphere and root anatomy of rice (Oryza sativa). Ann Bot 114:271-278. https://doi.org/10.1093/aob/mcu117

Ye Z, Baker AJ, Wong M-H, Willis AJ (1998) Zinc, lead and cadmium accumulation and tolerance in Typha latifolia as affected by iron plaque on the root surface. Aquat Bot 61:5567. https://doi.org/10.1016/S0304-3770(98)00057-6

Yu Y, Yuan S, Zhuang J, Wan Y, Wang Q, Zhang J, Li H (2018) Effect of selenium on the uptake kinetics and accumulation of and oxidative stress induced by cadmium in Brassica chinensis. Ecotoxicol Environ Saf 162:571-580. https://doi. org/10.1016/j.ecoenv.2018.07.041

Zhou XB, Li YY (2018) Effect of iron plaque and selenium on mercury uptake and translocation in rice seedlings grown in solution culture. Environ Sci Pollut Res (in print). https://doi. org/10.1007/s11356-018-3066-Z

Zhou J, Hao M, Liu Y-H, Fu Q, Zhu J, Hu H (2017) Physiological mechanism of different valences selenium in relieving cadmium stress of rape. J Plant Nutr Fertil 23:444-450

Zwolak I, Zaporowska H (2012) Selenium interactions and toxicity: a review. Cell Biol Toxicol 28:31-46. https://doi. org/10.1007/s10565-011-9203-9

Publisher's note Springer Nature remains neutral with regard to jurisdictional claims in published maps and institutional affiliations. 